\title{
Role of lung ultrasound in estimation of extravascular lung water in patients on regular hemodialysis
}

\author{
Nael Samir (M.D.) \\ Critical care department, Cairo University \\ Khaled Elkafas (M.D.) \\ Radiology Department, Cairo University \\ Ahmed Kamal (M.D.) \\ Critical Care Department, Cairo University
}

Ashraf Donia (M.B.B.CH)

DOI: $10.31364 / \mathrm{SCIRJ} / \mathrm{v} 7 . \mathrm{i3.2019.P0319621}$

http://dx.doi.org/10.31364/SCIRJ/v7.i3.2019.P0319621

\begin{abstract}
:
Background: Chest ultrasonography has recently been shown to be useful for the non-invasive assessment of extravascular lung water, Patients on maintenance hemodialysis are characterized by a condition of volume overload, these patients represent a unique model in which volume overload can be evaluated before and after a rapid fluid clearance determined by the dialytic session. Our aim of work was to assess efficacy of lung ultrasound in detecting extravascular lung water and volume over load.
\end{abstract}

Methods: Forty patients known as chronic renal failure patients on regular hemodialysis for more than 6 months were subjected to full history taking and physical examination, laboratory studies, echocardiography, and lung ultrasound, before and after dialysis session. Lung ultrasound and inferior vena cava measurements were performed immediately before and after dialysis. A standard echocardiography probe was used for the detection of lung comets. Examinations were performed in the supine position. Scanning of the anterior and lateral chest was performed on both sides of the chest, Lung comets (B lines) were calculated in 2 different planes both right and left (mid clavicular, mid axillary), to make total of 8 intercostal spaces examined for lung comets.

Results: Our study showed highly significant reduction of pulmonary B-lines (ULCs) following dialysis, significant linear regression between B-lines percentage reduction (delta B-lines \%) and delta weight $(\mathrm{kg})$, significant reduction in end inspiratory and end expiratory vena cava diameter, Also our study showed significant association between expiratory IVC diameter before dialysis and accumulated weight in respect to dry weight, but did not show significant association between expiratory vena cava diameter after dialysis and residual weight in respect to dry weight.

Conclusion: Ultrasound performed at the bedside can detect lung water and intravascular overload and their reduction after dialysis in yet asymptomatic patients.

Key words: Lung ultrasound, B-lines, Hemodialysis. 


\section{Introduction:}

Chronic volume expansion, either clinically apparent or occult, is a pervasive complication in patients with end stage renal disease (ESRD) maintained on dialysis (Kalantar-Zadeh K et al, 2009).

The use of lung ultrasonography to evaluate extravascular lung water and its consequences has received growing attention in different clinical areas, including, in recent years, end stage renal disease patients treated by hemodialysis.

Due to volume overload, dialysis patients often present with lung imbibition resembling pulmonary heart failure related congestion.

The presence of B-lines although often asymptomatic, underlines the capability of lung US to detect the signs of pulmonary imbibition even in a subclinical phase (Trezzi et al, 2011).

\section{AIM OF THE WORK:}

The aim of this work was to assess if lung ultrasound could detect pulmonary congestion (lung water imbibition) and fluid volume status and its rapid modification induced by dialysis, an experimental model of controlled rapid fluid loss in chronic hemodialysis patients.

Methods: Forty patients known as chronic renal failure on regular hemodialysis for more than 6 months were subjected to full history taking and physical examination, laboratory studies, echocardiography, and lung ultrasound, before and after dialysis session. Lung ultrasound and inferior vena cava measurements were performed immediately before and after dialysis. A standard echocardiography probe was used for the detection of lung comets. Examinations were performed in the supine position. Scanning of the anterior and lateral chest was performed on both sides of the chest, Lung comets (B lines) were calculated in 2 different planes both right and left (mid clavicular, mid axillary), to make total of 8 intercostal spaces examined for lung comets. Data was summarized using:

-Mean and SD for quantitative variables, which were normally distributed.

-Number and percent for qualitative variables.

-Comparison between qualitative variables were done using chi square test for qualitative variables while independent $t$ test for quantitative variables.

-Correlation was done to test for linear relations between variables; logistic regression analysis was done to test for significant predictors.

\section{-P value less than 0.05 was considered of statistically significance.}

\section{RESULTS:}

The present study included 40 patients with history of chronic hemodialysis more than 6 months of both sexes at the dialysis unit in the national institute of urology and nephrology .Demographic data and clinical characteristics of the studied patients is shown in Table 1\&2:

Table (1): Demographic data of the studied patients. 


\begin{tabular}{|c|c|c|c|}
\hline \multicolumn{2}{|c|}{ Parameter } & Number & Percentage \\
\hline Age & Mean & \multicolumn{2}{|c|}{52.4} \\
\hline & SD & \multicolumn{2}{|c|}{11.5} \\
\hline \multirow[t]{2}{*}{ Sex } & male & 22 & 55 \\
\hline & female & 18 & 45 \\
\hline Diabetes mellitus & & 11 & 27.5 \\
\hline Hypertension & & 26 & 65 \\
\hline Chronic liver disease & & 8 & 20 \\
\hline Hypertensive heart disease & & 26 & 65 \\
\hline
\end{tabular}

Sex, DM, HTN, chronic liver disease and hypertensive heart disease are expressed as number and percentage while age is expressed as mean $\pm \mathrm{SD}$.

Our study was conducted on 22 male (55\%) and 18 female (45\%) with (mean \pm SD) age of (52.4 years \pm 11.5$)$.

Patients with diabetes mellitus were $27.5 \%$, patients with hypertension were $65 \%$, patients with chronic liver disease were $20 \%$ and patients with hypertensive heart disease were $65 \%$ as shown in Table 4.

Table (2): Demographic data of the studied patients.

\begin{tabular}{|l|c|c|}
\hline \multicolumn{1}{|c|}{ Parameter } & Mean & SD \\
\hline Dry weight & 76.4 & 1.75 \\
\hline Accumulated weight & 3.13 & 1.18 \\
\hline Actual weight & 79.5 & 1.76 \\
\hline Residual weight & 0.22 & 0.33 \\
\hline
\end{tabular}

Dry weight, accumulated weight, actual weight and residual weight are expressed as mean $\pm \mathrm{SD}$.

Patient's dry weight was $76.4 \pm 1.75 \mathrm{~kg}$, accumulated weight was $3.13 \pm 1.18 \mathrm{~kg}$, actual weight was $79.5 \pm 1.76 \mathrm{~kg}$ and residual weight was $0.22 \pm 0.33 \mathrm{~kg}$ as shown in Table 2 .

Table (3): Comparison between vital data before and after dialysis.

\begin{tabular}{|l|c|c|c|c|c|c|}
\hline & \multicolumn{2}{|c|}{ Before dialysis } & \multicolumn{3}{c|}{ After dialysis } & p value \\
\hline Parameter & Median & minimum & Maximum & Median & minimum & Maximum \\
& & & & & & \\
\hline
\end{tabular}




\begin{tabular}{|l|c|c|c|c|c|c|c|}
\hline Systolic BP & 130 & 80 & 210 & 120 & 60 & 80 & 0.02 \\
\hline Diastolic BP & 80 & 40 & 110 & 70 & 30 & 110 \\
\hline Pulse rate & 84 & 64 & 120 & 85 & 60 & 110 \\
\hline Respiratory rate & 22 & 16 & 40 & 20 & 14 & 44 & 0.12 \\
\hline
\end{tabular}

All parameters are expressed as median (minimum - maximum)

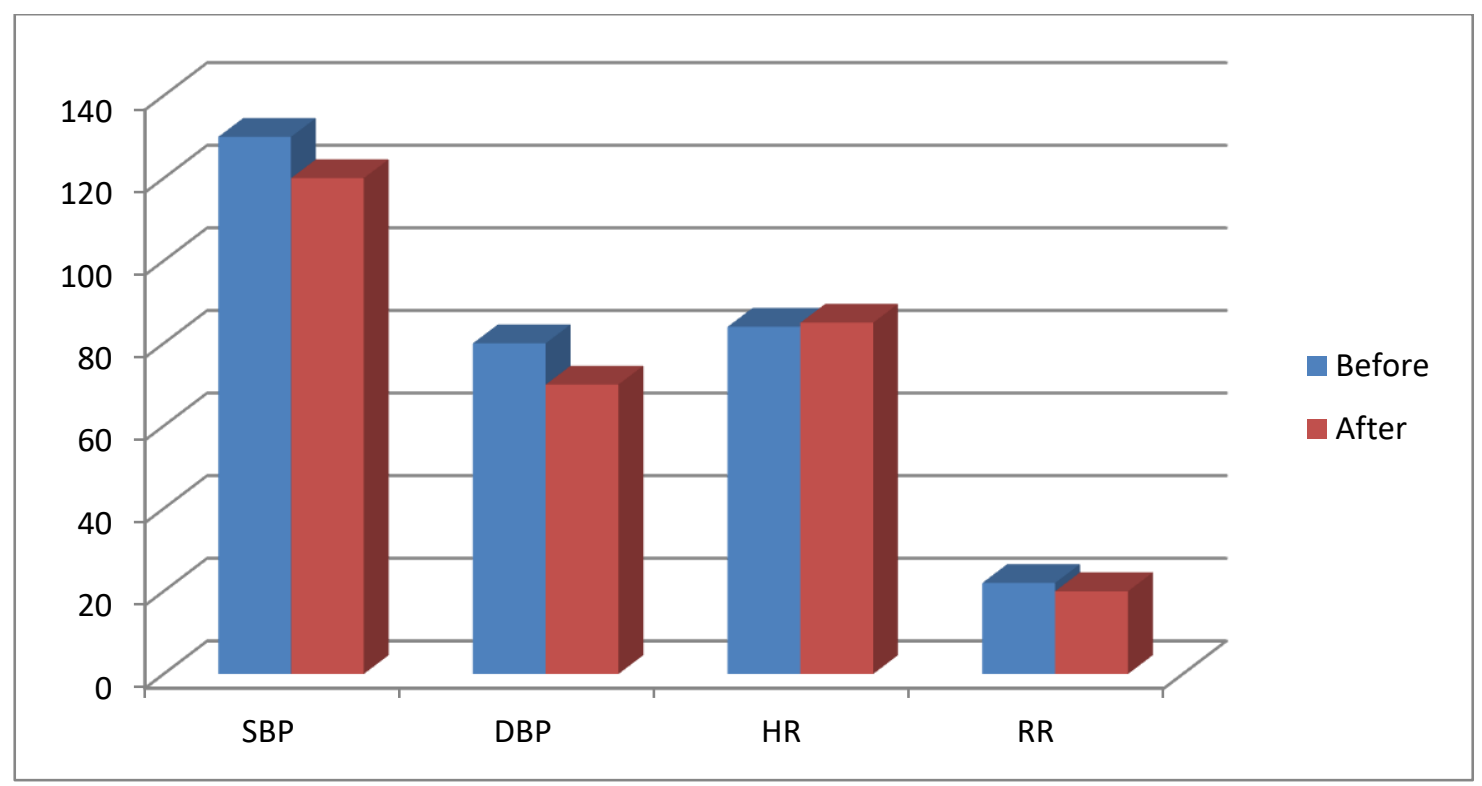

Figure (1): Comparison between vital data before and after dialysis.

There was statistically significant difference between systolic blood pressure that was higher before than after dialysis with $\mathrm{p}$ value 0.02 , diastolic blood pressure that was higher before than after dialysis with $\mathrm{p}$ value 0.012 , respiratory rate that was higher before than after dialysis with $\mathrm{p}$ value 0.001 while pulse rate shows statistically non-significant increase after dialysis with $\mathrm{p}$ value 0.12 . 
Table (4): Comparison between number of B-lines before and after dialysis.

\begin{tabular}{|c|c|c|c|c|c|}
\hline Number of B-lines & Mean & $\pm \mathrm{SD}$ & Mean Diff. & t-test & $\mathrm{p}$ value \\
\hline Before dialysis & 19.15 & 9.49 & \multirow{2}{*}{12.50} & \multirow{2}{*}{7.13} & \multirow{2}{*}{$<0.001$} \\
\hline After dialysis & 6.65 & 4.69 & & & \\
\hline
\end{tabular}

This table shows highly statistically significant decrease of B lines after dialysis with p value $<0.001$.

\section{B-lines before dialysis $\quad$ B-lines after dialysis}

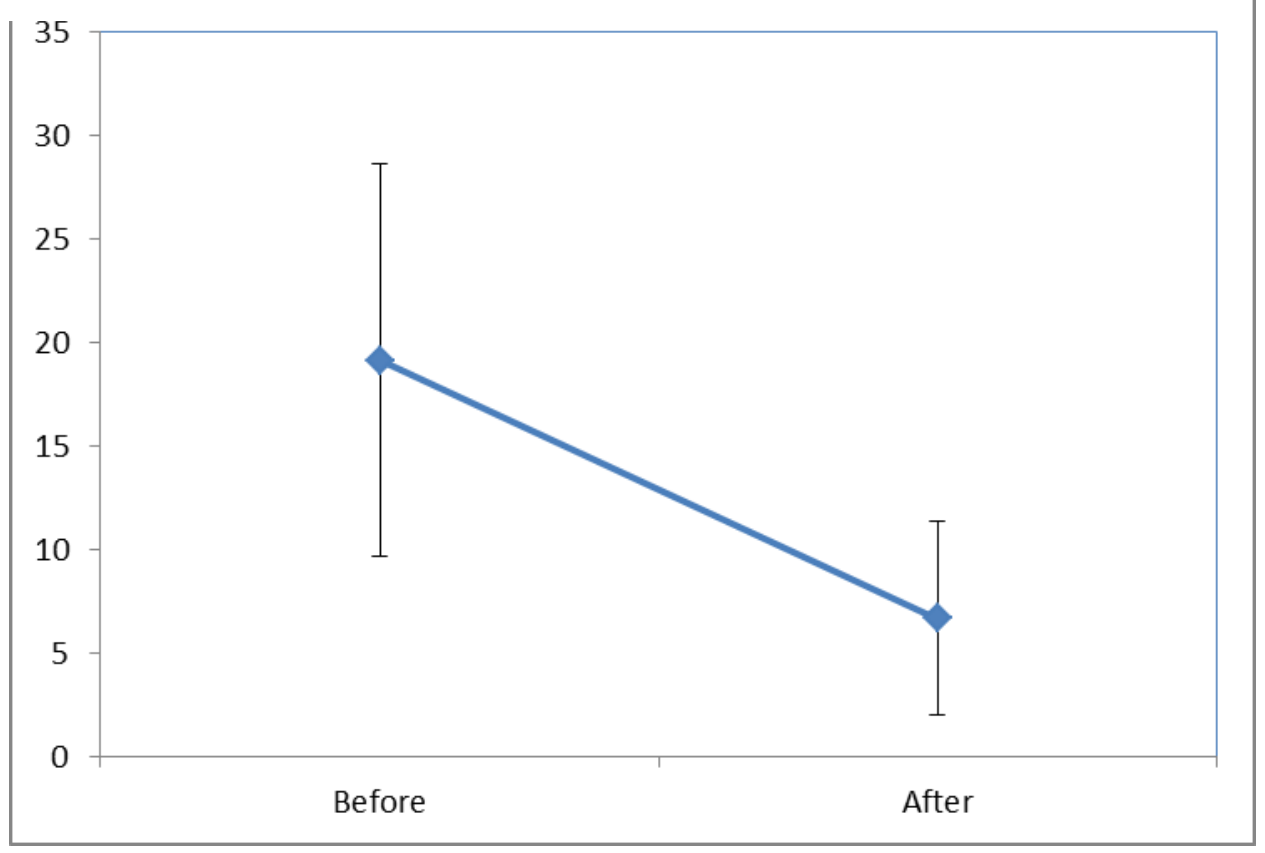

Figure (2): Comparison between number of B-lines before and after dialysis. 


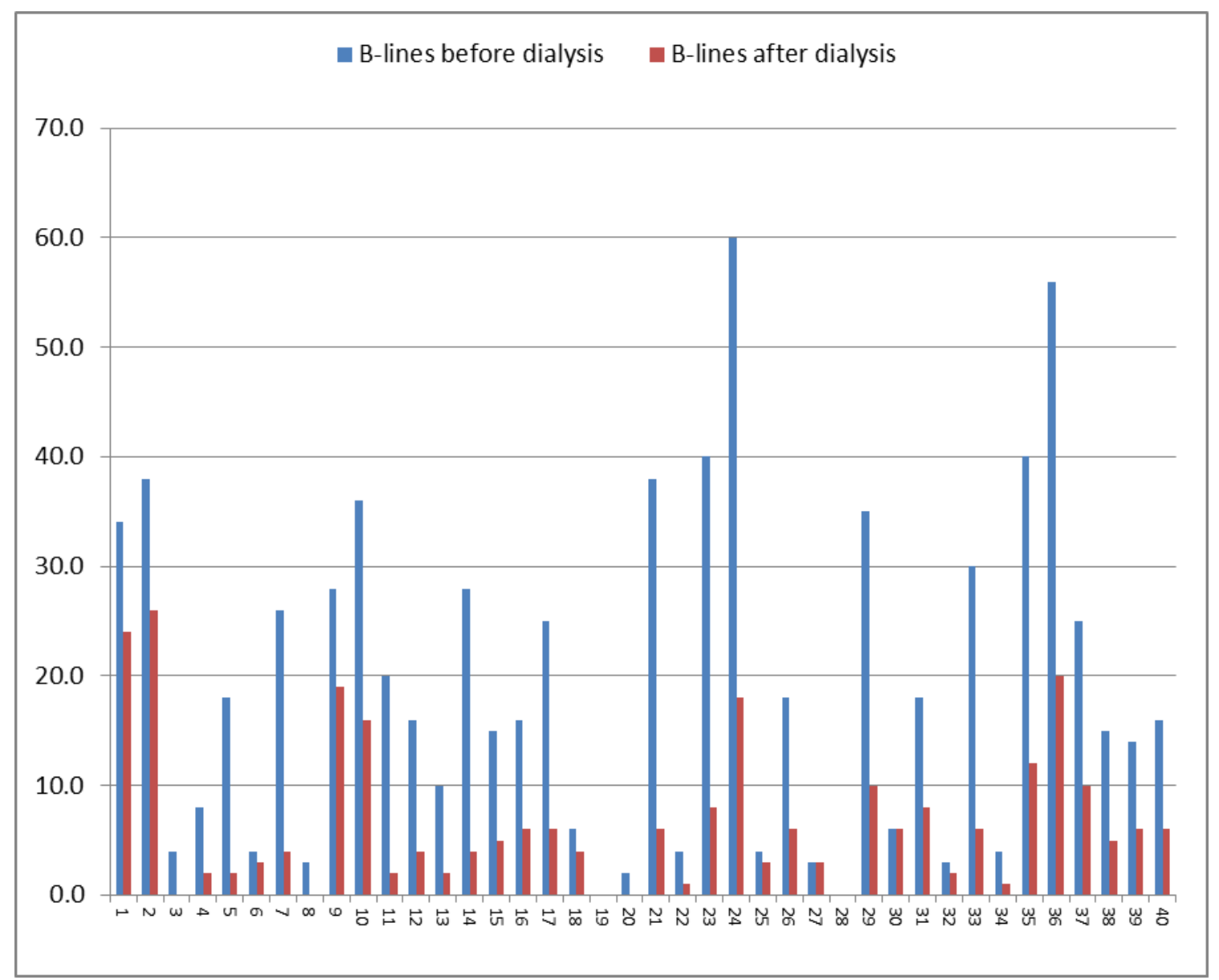

Figure (3): Comparison between number of B-lines before and after dialysis for each patient.

Table (5):Linear regression between delta B-lines percentage $\%$ and delta weight (kg).

\begin{tabular}{|c|c|c|}
\hline & & Delta weight (kg) \\
\hline \multirow{2}{*}{ Delta B-lines\% } & $\mathrm{r}$ & 0.322 \\
\cline { 2 - 3 } & $\mathrm{p}$ & 0.045 \\
\hline
\end{tabular}




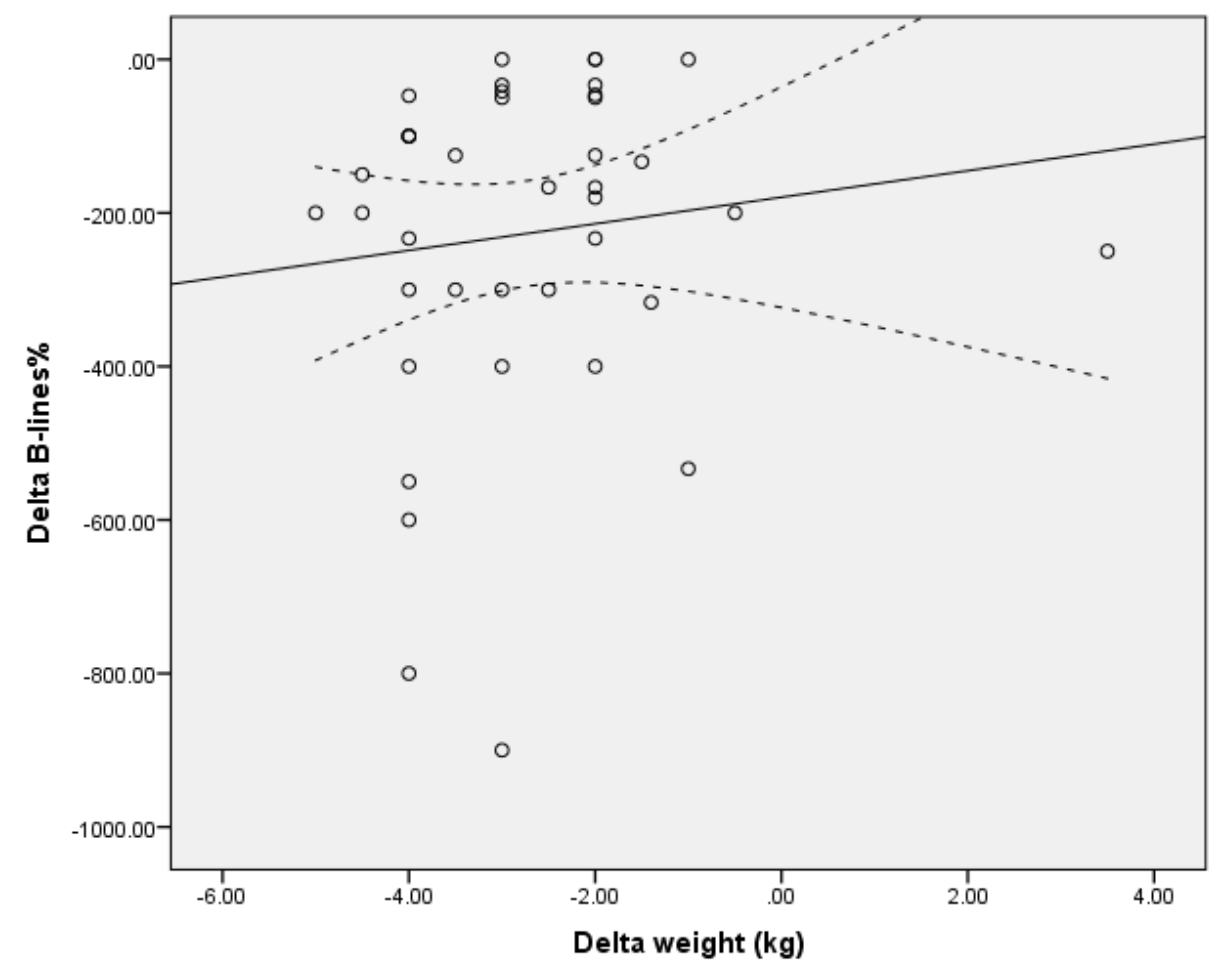

Figure (4): Linear regression between delta B-lines \% and delta weight (kg).

There were significant results of linear regression between delta B-lines percentage \% and delta weight (kg) with $\mathrm{p}$ value $0.045 \&$ r 0.322 .

Table (6): Linear regression between number of B-lines before dialysis and accumulated weight (kg).

\begin{tabular}{|c|c|c|}
\hline & & Accumulated weight $(\mathrm{kg})$ \\
\hline \multirow{2}{*}{ B-lines before dialysis } & $\mathrm{r}$ & 0.011 \\
\cline { 2 - 3 } & $\mathrm{p}$ & 0.945 \\
\hline
\end{tabular}




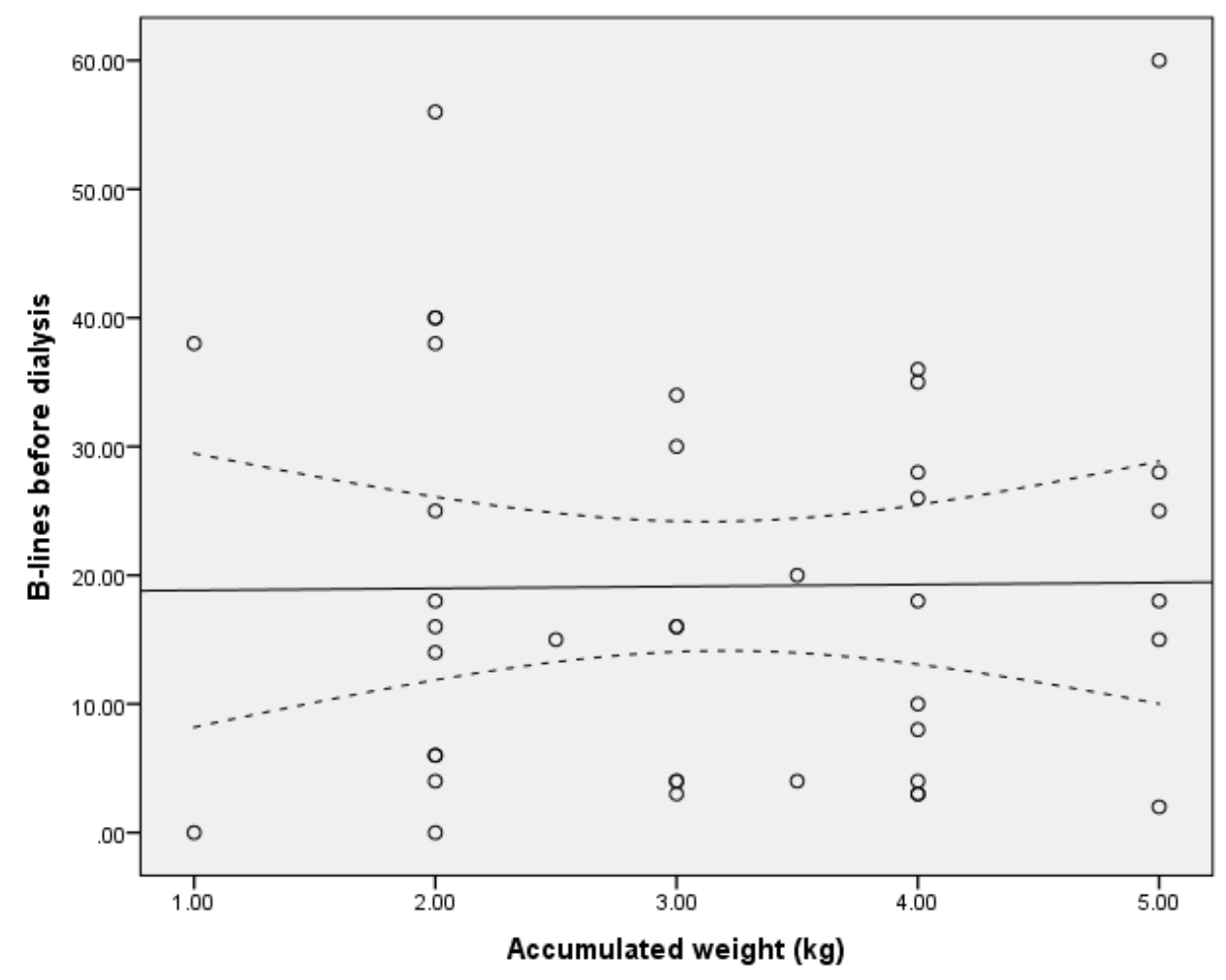

Figure (5):Linear regression between B-lines before dialysis and accumulated weight $(\mathrm{kg})$.

There was non-significant results of linear regression between number of B-lines before dialysis and accumulated weight $(\mathrm{kg})$ with $\mathrm{p}$ value 0.94

Table (7):Linear regression between number of B-lines after dialysis and residual weight $(\mathrm{kg})$.

\begin{tabular}{|c|c|c|}
\hline & & Residual weight $(\mathrm{kg})$ \\
\hline \multirow{2}{*}{ B-lines after dialysis } & $\mathrm{r}$ & -0.005 \\
\cline { 2 - 4 } & $\mathrm{p}$ & 0.977 \\
\hline
\end{tabular}




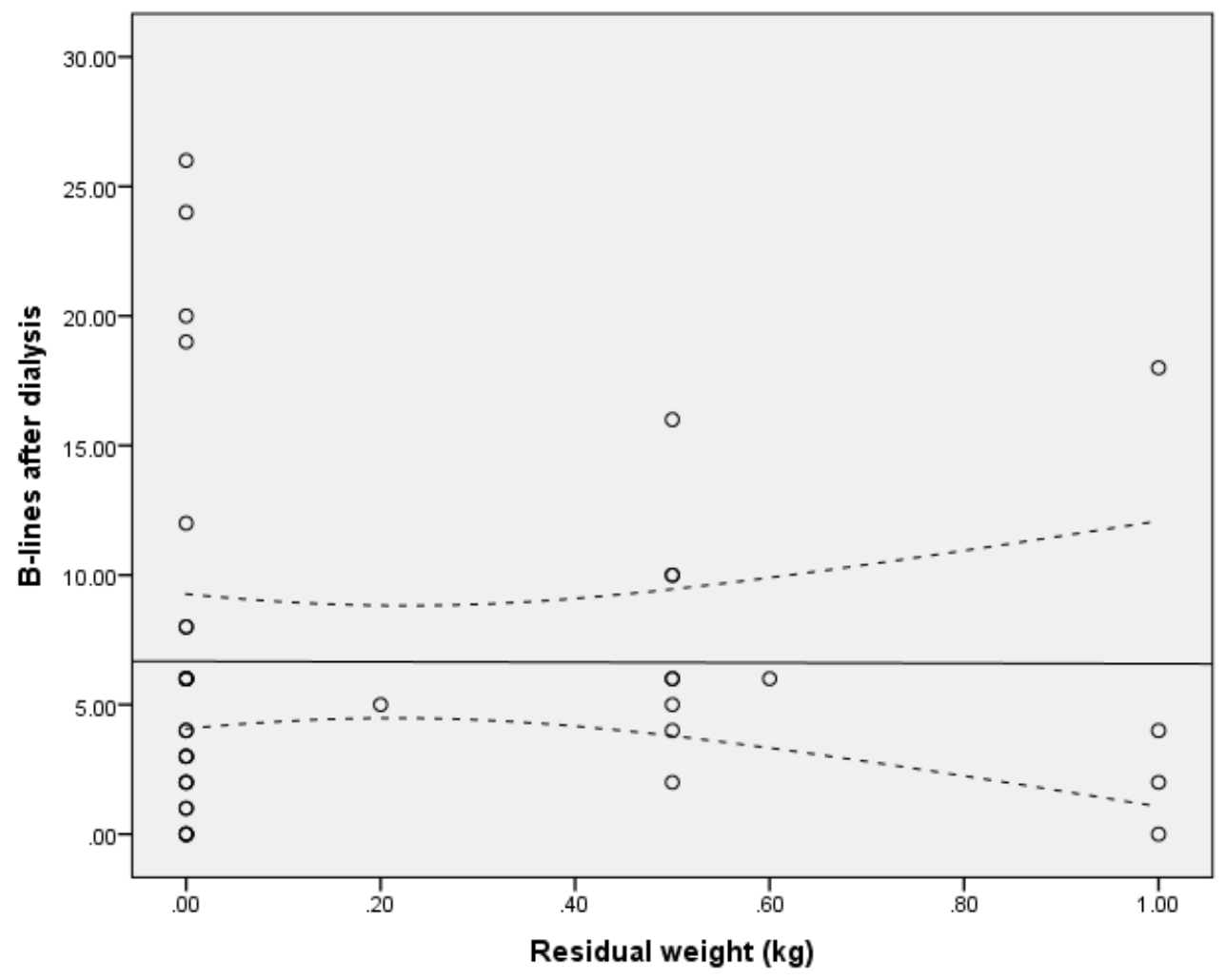

Figure (6): linear regression between B-lines after dialysis and residual weight (kg).

There was non-significant results of linear regression between number of B-lines after dialysis and residual weight (kg) with $\mathrm{p}$ value 0.97

Table (8):Comparison between inferior vena cava (end inspiratory\& end expiratory ) diameter (mm) before and after dialysis.

\begin{tabular}{|c|c|c|c|c|c|}
\hline & \multicolumn{2}{|c|}{ Before dialysis } & \multicolumn{2}{c|}{ After dialysis } & p value \\
\hline Parameter & Mean & SD & Mean & SD \\
\hline IVC EI & 14.7 & 1.4 & 12.5 & 1.37 & 0.00 \\
\hline IVC EE & 19.6 & 1.8 & 13.6 & 0.47 & 0.00 \\
\hline
\end{tabular}

All parameters are expressed as mean \pm (SD). 


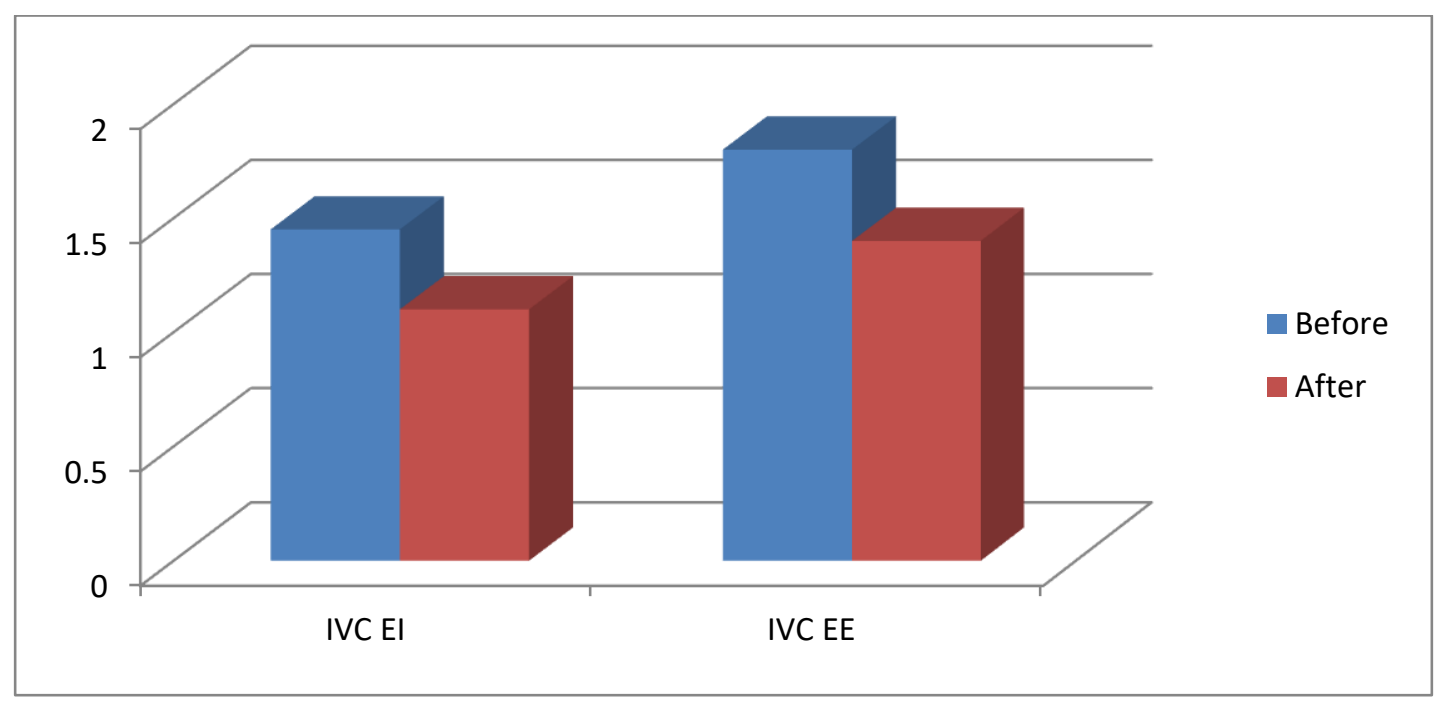

Figure (7): Comparison between inferior vena cava (end inspiratory \& end expiratory) diameter ( $\mathrm{mm}$ ) before and after dialysis.

IVC EI and IVC EE shows statistically significant decrease after dialysis with p value 0.00 . 
Table (9): Linear regression between End exp. vena cava diameter ( $\mathrm{mm})$ before dialysis and accumulated weight (kg).

\begin{tabular}{|c|c|c|}
\hline & & Accumulated weight $(\mathrm{kg})$ \\
\hline \multirow{2}{*}{$\begin{array}{c}\text { End exp. vena cava diameter before } \\
\text { dialysis }\end{array}$} & $\mathrm{r}$ & $0.402 *$ \\
\cline { 2 - 3 } & $\mathrm{p}$ & 0.010 \\
\hline
\end{tabular}

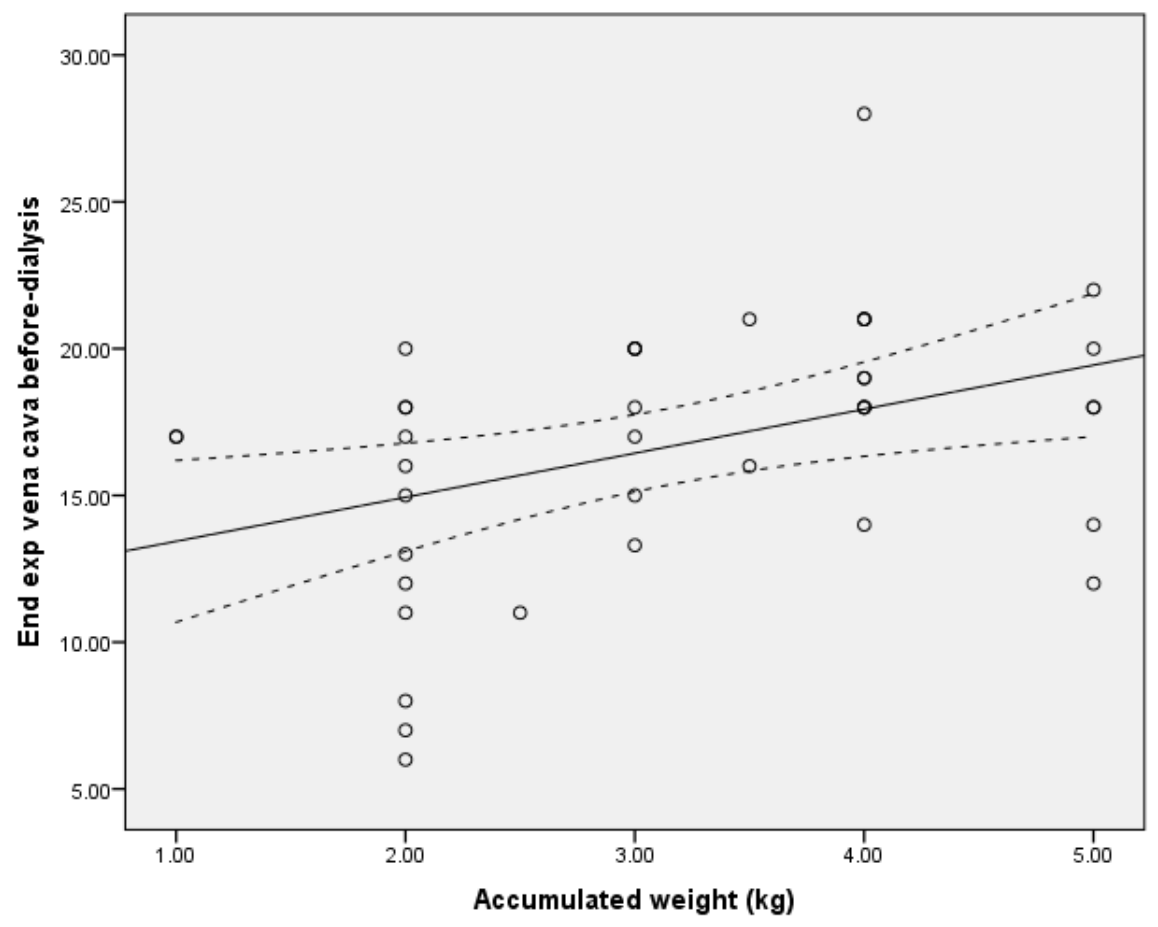

Figure (8): Linear regression between End exp. vena cava diameter ( $\mathrm{mm}$ ) before dialysis and accumulated weight (kg).

There were significant results of linear regression between End exp. vena cava diameter before dialysis and accumulated weight $(\mathrm{kg})$ with p value 0.01 .

Table (10): Linear regression between End exp. vena cava diameter (mm) after dialysis and residual weight (kg).

\begin{tabular}{|l|c|c|}
\hline & & Residual weight (kg) \\
\hline \multirow{2}{*}{ End exp vena cava diameter after dialysis } & $\mathrm{r}$ & -0.133 \\
\cline { 2 - 4 } & $\mathrm{p}$ & 0.414 \\
\hline
\end{tabular}




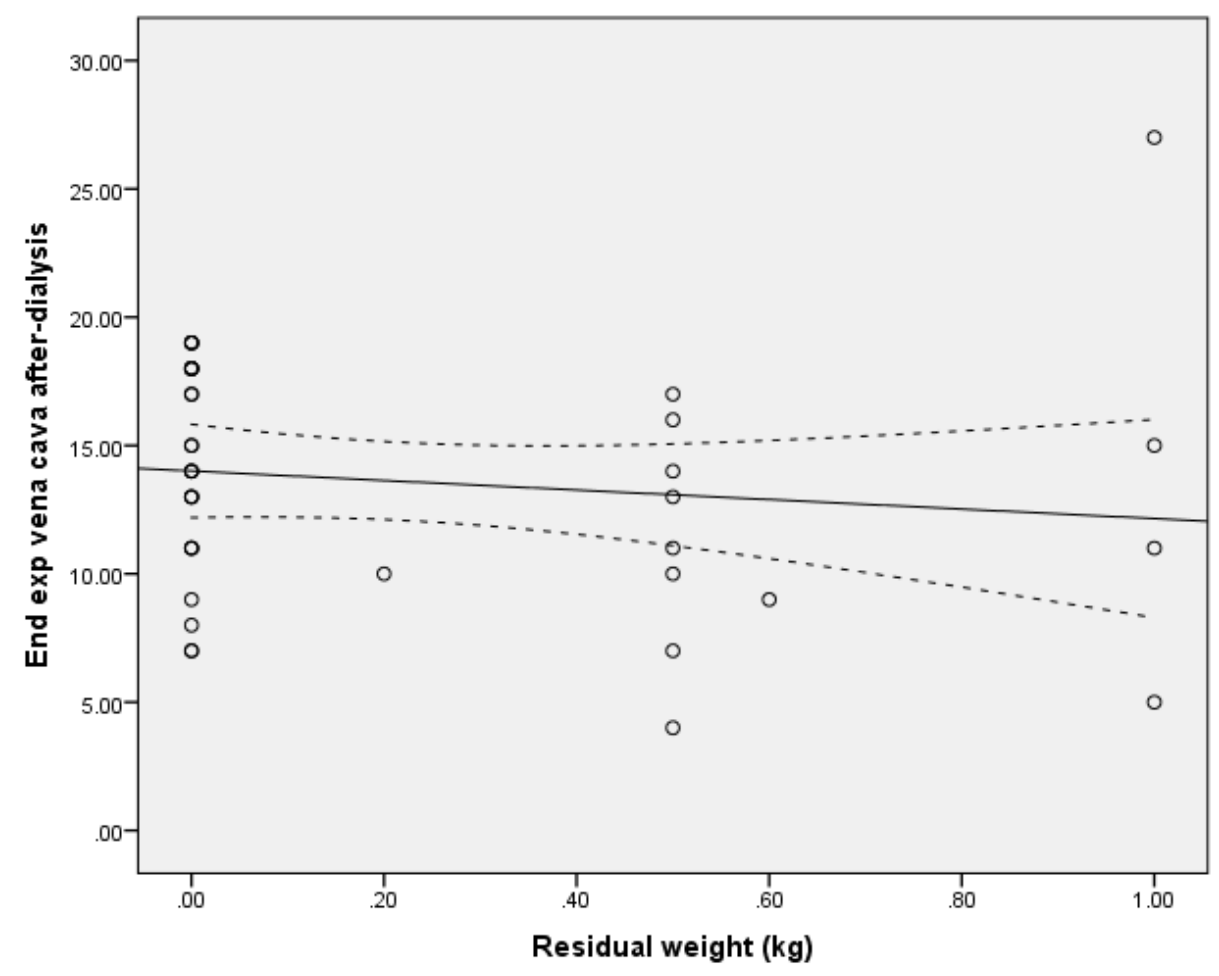

Figure (9): Linear regression between End exp. vena cava diameter (mm) after dialysis and residual weight (kg).

There was non significant results of linear regression between End exp vena cava diameter after dialysis and residual weight $(\mathrm{kg})$ with $\mathrm{p}$ value 0.41 .

Table (1):Linear regression between delta expiratory vena cava diameter (mm) and delta weight $(\mathrm{kg})$.

\begin{tabular}{|l|c|c|}
\hline & & Delta weight $(\mathrm{kg})$ \\
\hline \multirow{3}{*}{ Delta expiratory vena cava diameter } & $\mathrm{R}$ & 0.057 \\
\cline { 2 - 3 } & $\mathrm{P}$ & 0.725 \\
\hline
\end{tabular}




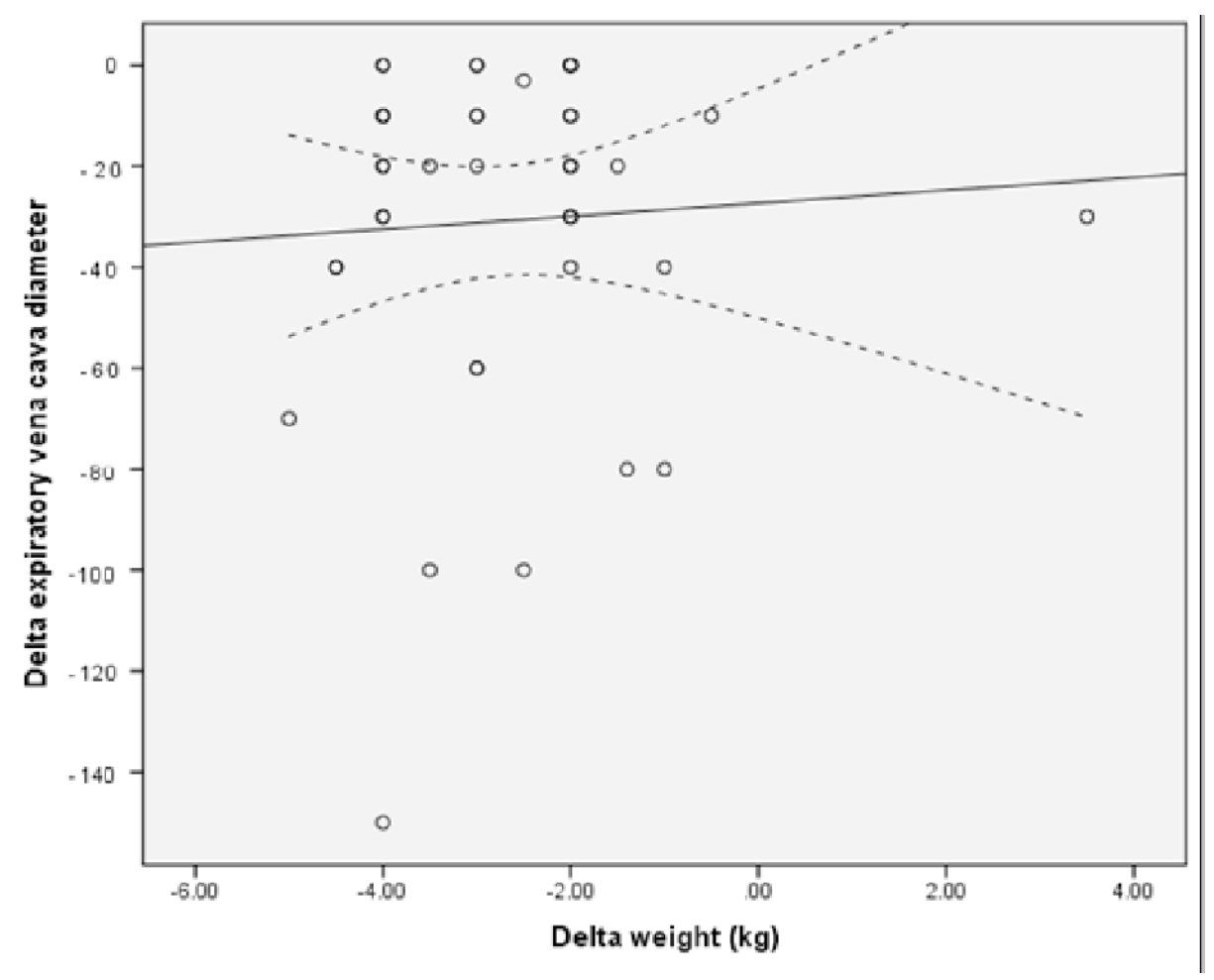

Figure (10): Linear regression between delta expiratory vena cava diameter and delta weight $(\mathrm{kg})$.

There was non-significant results of linear regression between delta expiratory vena cava diameter and delta weight $(\mathrm{kg})$ with $\mathrm{p}$ value 0.72 .

Table (2): Linear regression between delta B-lines \% and delta expiratory vena cava diameter.

\begin{tabular}{|l|c|c|}
\hline & & Delta B-lines\% \\
\hline \multirow{2}{*}{ Delta expiratory vena cava diameter } & $\mathrm{r}$ & -0.198 \\
\cline { 2 - 4 } & $\mathrm{p}$ & 0.222 \\
\hline
\end{tabular}




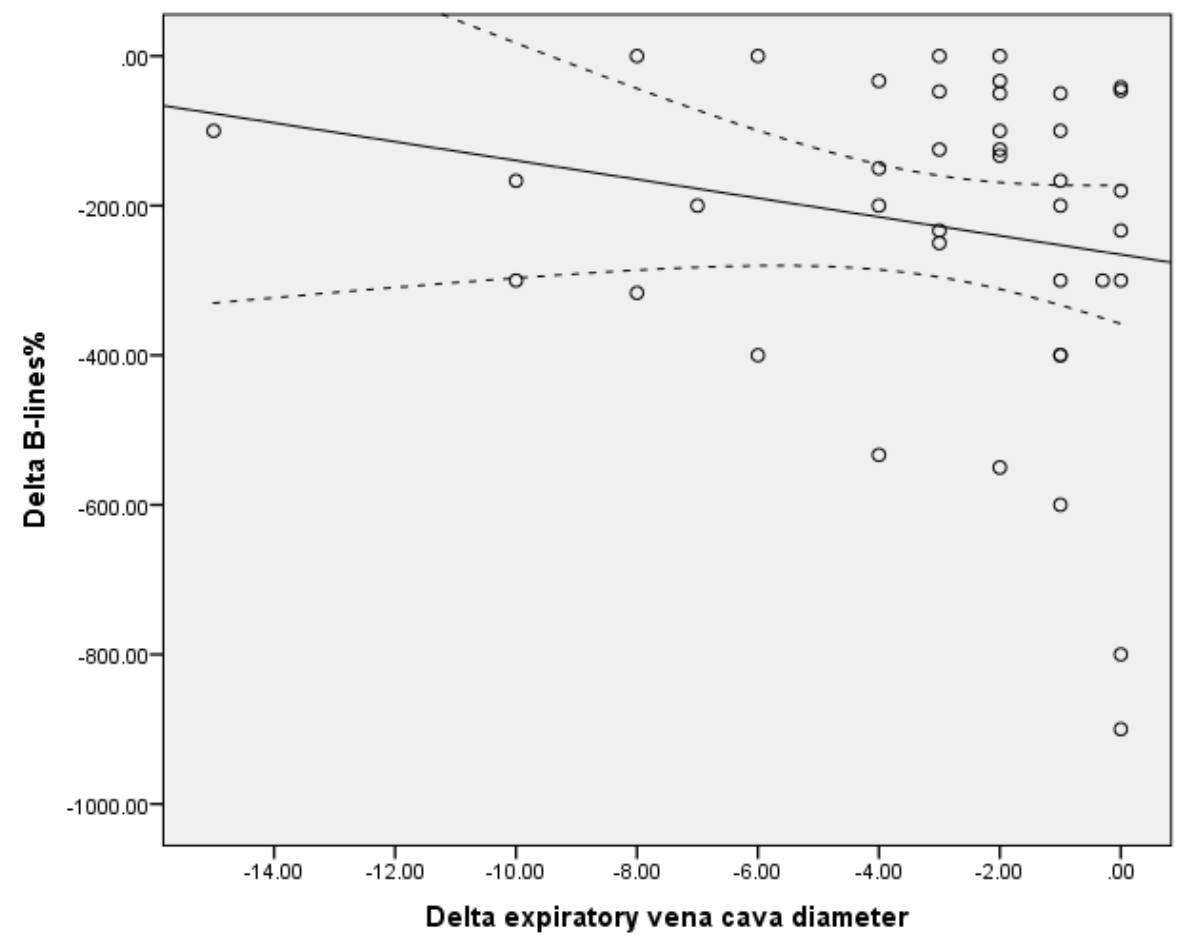

Figure (11): Linear regression between delta B-lines \% and delta expiratory vena cava diameter.

There was non-significant results of linear regression between delta B-lines $\%$ and delta expiratory vena cava diameter with $\mathrm{p}$ value 0.222 .

Table (3): $\quad$ Comparison between Arterial Blood Gases values before and after dialysis.

\begin{tabular}{|l|c|c|c|c|c||}
\hline \multirow{2}{*}{} & \multicolumn{2}{|c|}{ Before dialysis } & \multicolumn{2}{c|}{ After dialysis } & p value \\
\hline Parameter & Mean & SD & Mean & SD & \\
\hline $\mathbf{p H}$ & 7.35 & 0.05 & 7.43 & 0.05 & 0.00 \\
\hline paCO$_{2}$ & 30.5 & 3.6 & 31.8 & 5.6 & 0.22 \\
\hline $\mathbf{H C O}_{3}$ & 17.4 & 2.5 & 21.1 & 2.9 & 0.00 \\
\hline $\mathbf{p a O}_{2}$ & 95.9 & 1.5 & 91.0 & 1.5 & 0.015 \\
\hline $\mathbf{s O}_{2}$ & 95.9 & 4.3 & 96.4 & & 0.09 \\
\hline
\end{tabular}




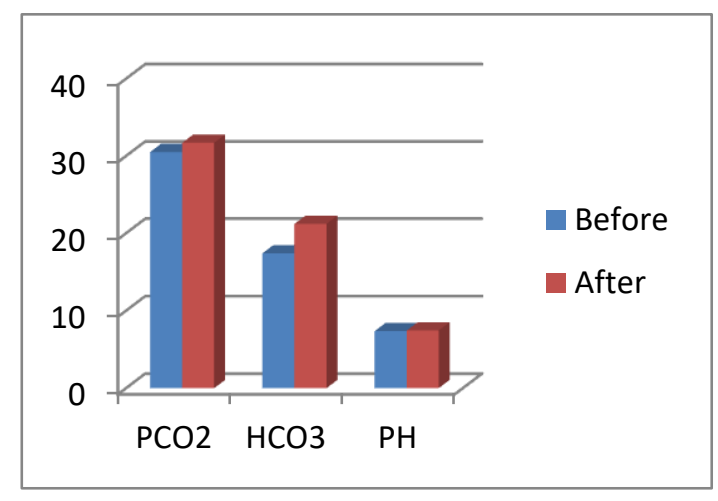

$\mathbf{A}$

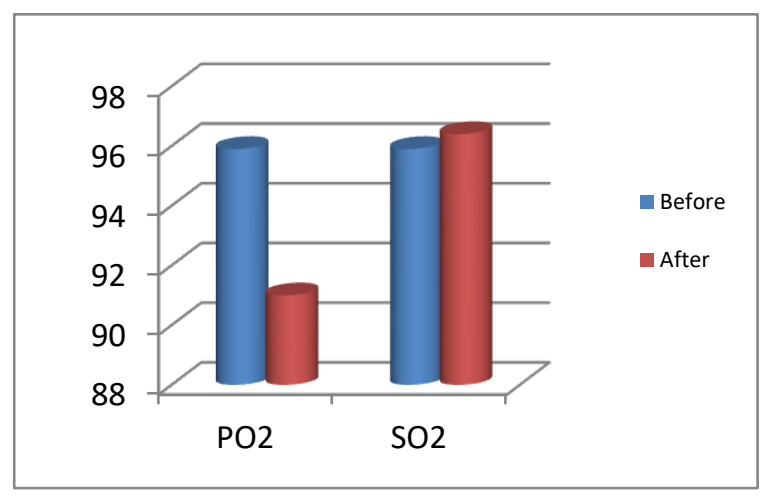

B

Figure (12) (A, B): Comparison between Arterial Blood Gases values before and after dialysis.

PH\& $\mathrm{HCO}_{3}$ show statistically significant increase after dialysis with $\mathrm{p}$ value $0.00, \mathrm{paO}_{2}$ shows statistically significant decrease after dialysis with $\mathrm{p}$ value 0.015 , while $\mathrm{paCO}_{2} \& \mathrm{sO}_{2}$ show non-significant increase after dialysis.

\section{Discussion:}

The use of lung ultrasonography to evaluate extravascular lung water and its consequences has received growing attention in different clinical areas, including, in recent years, end stage renal disease patients treated by hemodialysis.

Due to volume overload, dialysis patients often present with lung imbibition resembling pulmonary heart failure related congestion. The presence of B-lines although often asymptomatic, underlines the capability of lung US to detect the signs of pulmonary imbibition even in a subclinical phase (Trezzi et al, 2011).

Patients with end stage renal failure on dialysis represent a stable cohort who will have significant fluid shifts around the time of their renal replacement therapy and constitute a useful cohort to study real time changes in fluid status and lung water where controlled fluid withdrawal is rapidly and reproducibly performed (Noble VE et al, 2009).

Results in the dialysis population share the convincing data on the contemporaneous relationship between EVLW\& ultrasonography B-line measurement, supporting the role of ultrasound as a useful dynamic means of estimating the effects of changes in fluid status on the lung.

The aim of our study was to assess the use of lung ultrasound (LUS) to detect lung water and intravascular overload and their reduction after dialysis in as yet asymptomatic patients.

The study included 40 patients with ESRD on regular hemodialysis for more than 6 months, and was performed in the national institute of urology and nephrology, patients were recruited from hemodialysis unit over 6 months (From January 2016 to July 2016).

Baseline demographic data were collected including name, gender and age. All participants were interviewed for their medical history, including presence of diabetes or hypertension, history of previous medical problems and the weight (before and after hemodialysis session). Vital signs were measured before and after hemodialysis session, Arterial blood gases were obtained from each participant (before and after hemodialysis session. 
Echocardiography performed before dialysis and lung ultrasound was performed (before and after dialysis), any patient with $\mathrm{EF}<40 \%$ was excluded from the study .

Our study was conducted on 22 male (55\%) and 18 female (45\%) with (mean \pm SD ) age of our patients $(52.4 \pm 11.5)$, patients with diabetes mellitus was $27.5 \%$, patients with hypertension was $65 \%$. patients with chronic liver disease was $20 \%$ and patients with hypertensive heart disease was $65 \%$.

There was statistically significant difference between systolic blood pressure that was higher before than after dialysis with $\mathrm{p}$ value 0.02 , diastolic blood pressure that was higher before than after dialysis with $\mathrm{p}$ value 0.012 , respiratory rate that was higher before than after dialysis with $\mathrm{p}$ value 0.001 while pulse rate shows statistically non-significant increase after dialysis with $\mathrm{p}$ value 0.12 .

On the other hand Trezzi and colleagues found non-significant difference as regard mean arterial blood pressure (Trezzi et al, 2011).

We found a highly significant reduction of pulmonary B-lines (ULCs) following dialysis, demonstrating a rapid clearance of lung imbibition after the removal of volume overload with $(19.1 \pm 9.4$ versus $6.6 \pm 4.6) \quad \mathrm{p}$ value $<0.001$.

Our findings goes with Noble and colleagues who examined 40 patients with end stage renal failure before and after dialysis, and found that there was a significant reduction in B-lines after dialysis with $p$ value $<0.001$ (Noble VE et al 2009).

Mallamaci and colleagues performed chest ultrasound before and after dialysis and found that B-line count significantly reduced after dialysis with $\mathrm{p}$ value $<0.001$ (Mallamaci $\mathbf{F}$ et al 2010).

Also Trezzi and colleagues found significant reduction of the mean value of total number of B-lines after dialysis (24.8 \pm 25.3 versus $8.6 \pm 9.8$ ) with $p$ value $<0.001$ (Trezzi et al, 2011).

Also Vitturi and colleagues found significant reduction of the mean value of total number of B-lines after dialysis (3.13 \pm 3.4 versus $1.41 \pm 2.47$ ) with $p$ value $=0.00$ (Vitturi et al, 2014).

Also Basso and colleagues found significant reduction of the mean value of total number of B-lines after dialysis (20 \pm 11.5 versus $12.7 \pm 7.1$ ), $\mathrm{p}$ value $<0.001$ (Basso et al, 2013).

An interesting point in our study that reduction in B-line count was significantly related to weight loss occurring after dialysis confirming the direct relationship between pulmonary B-lines and water balance.

There was significant linear regression between B-lines percentage reduction (delta B-lines \%) and delta weight ( $\mathrm{kg}$ ) with $\mathrm{p}$ value $=0.045$ denoting the efficiency of LUS in detection of decrease in EVLW in response to decrease of body weight.

Also Trezzi and colleagues found similar results, There was significant linear regression between B-lines percentage reduction versus weight loss (delta weight) after dialysis with $\mathrm{p}$ value $<0.05$ (Trezzi et al, 2011).

Also Vitturi and colleagues found similar results, There was significant linear regression between B-lines reduction versus weight loss (delta weight) after dialysis with $\mathrm{p}$ value $=0.007$ (Vitturi et al, 2014).

We did not find a significant association between B-lines (ULCs) before dialysis and accumulated weight in respect to dry weight with $\mathrm{p}$ value $=0.9$ or between B-lines (ULCs) after dialysis and residual weight in respect to dry weight with $\mathrm{p}$ value $=0.4$. 
While Trezzi and colleagues found a significant association between B-lines (ULCs) before dialysis and accumulated weight in respect to dry weight with $\mathrm{p}$ value $<0.05$. Also between B-lines (ULCs) after dialysis and residual weight in respect to dry weight with $\mathrm{p}$ value $<0.01$ (Trezzi et al, 2011).

This may be explained by higher accumulated weight in their study group in contrast to our group of patients (3.4 vs. 3.1) $\mathrm{Kg}$.

We also investigated inferior vena cava diameter before and after dialysis session in order to evaluate the changes in intravascular volume.

There was a significant reduction in end inspiratory and end expiratory vena cava diameter after dialysis.

IVC EI shows statistically significant decrease after dialysis $(14.7 \pm 1.4$ vs. $12.5 \pm 1.37)$ with $\mathrm{p}$ value $=0.00$

Also , IVC EE shows statistically significant decrease after dialysis $(19.6 \pm 1.8$ vs $13.6 \pm 0.47)$ with $\mathrm{p}$ value $=0.00$

Our findings go with Trezzi and colleagues who found significant reduction of end inspiratory and end expiratory vena cava diameter after dialysis.

End inspiratory vena cava diameter $(\mathrm{mm})$ before and after dialysis was $(10.5 \pm 5.7 \& 7.6 \pm 5.3)$ respectively with $\mathrm{p}$ value $<$ 0.001 .

Also, End expiratory vena cava diameter $(\mathrm{mm})$ before and after dialysis was $(16.6 \pm 3.8 \& 11.9 \pm 4.6)$ respectively with $\mathrm{p}$ value $<0.001 \quad$ (Trezzi et al, 2011).

Vitturi and colleagues found significant reduction of end inspiratory and end expiratory vena cava diameter after dialysis.

End inspiratory vena cava diameter $(\mathrm{mm}) \quad$ before diaylsis and after dialysis was $\quad(11.9 \pm 5.9 \& 9.5 \pm 5.1)$ respectively with $\mathrm{p}$ value $=0.001$.

Also, End expiratory vena cava diameter $(\mathrm{mm})$ before and after dialysis was $(17.1 \pm 5.8 \& 13.7 \pm 5.5)$ respectively with $\mathrm{p}$ value $=0.001$ (Vitturi et al, 2014).

Also Basso and colleagues found significant reduction of end inspiratory and end expiratory vena cava diameter after dialysis.

End inspiratory vena cava diameter $(\mathrm{mm})$ before and after dialysis was $(5.4 \pm 2.1 \& 3.9 \pm 1.9)$ respectively with p value $<$ 0.001 .

Also, End expiratory vena cava diameter $(\mathrm{mm})$ before and after dialysis was $(6.8 \pm 2.4 \& 5.4 \pm 2)$ respectively with p value $<0.001$ (Basso et al, 2013).

We found a significant association between expiratory vena cava diameter before dialysis and accumulated weight in respect to dry weight with $\mathrm{p}$ value $=0.01$, but we did not find a significant association between expiratory vena cava diameter after dialysis and residual weight in respect to dry weight with $\mathrm{p}$ value $=0.41$.

Also There was non-significant linear regression between delta expiratory vena cava diameter with neither delta weight $(\mathrm{kg})$ with $\mathrm{p}$ value $=0.72$ nor $\mathrm{B}$ line reduction $($ delta $\mathrm{B}$ lines $)$ with $\mathrm{p}$ value $=0.22$. 
Our data goes with what was mentioned by Trezzi and colleagues who found a significant association between expiratory vena cava diameter before dialysis and accumulated weight in respect to dry weight with $p$ value $<0.001$, but they did not find a significant association between expiratory vena cava diameter after dialysis and residual weight in respect to dry weight $(p=0.063)$

Also Trezzi and colleagues found non-significant association between delta expiratory vena cava diameter with neither weight loss (delta weight) in respect to dry weight with $\mathrm{p}$ value $=0.59$ nor $\mathrm{B}$ line reduction (delta $\mathrm{B}$ lines ) with $\mathrm{p}$ value $=0.28$ (Trezzi et al, 2011).

However Vitturi and colleagues who found no significant association between delta expiratory vena cava diameter and weight loss (delta weight) in respect to dry weight with $\mathrm{p}$ value $=0.59$, they found significant association between delta expiratory vena cava diameter and $B$ line reduction (delta $B$ lines) with $\mathrm{p}$ value $=0.04 \quad$ (Vitturi et al, 2014).

A possible interpretation of these results could be the different correlation of inferior vena cava and LUS, while the first reflects the intra vascular filling grade, the latter reflects the grade of extravascular fluid in the lung interstitium.

We also investigated $\mathrm{ABG}$ values before and after a hemodialysis session. Plasma bicarbonate $\left(\mathrm{HCO}_{3}\right)$ and $\mathrm{pH}$ increased significantly after HD, $(17.4 \pm 2.5 \& 7.35 \pm 0.05)$ before HD versus $(21.1 \pm 2.9 \& 7.43 \pm 0.05)$ after $\mathrm{HD}$ with $\mathrm{p}$ value $=0.00$ for each.

Safa javid and colleagues found similar results as they investigated ABG values before and after a hemodialysis session. Plasma bicarbonate $\left(\mathrm{HCO}_{3}\right)$ and $\mathrm{pH}$ increased significantly after $\mathrm{HD}(\mathrm{p}=0.002$ and $\mathrm{p}=0.018$, respectively) (Safa j et al, 2011).

As regards $\mathrm{paCO}_{2}$ we recognized no significant increase $(30.5 \pm 3.6$ versus $31.8 \pm 5.6)$ with $\mathrm{p}$ value $=0.22$, however they found significant decrease in $\mathrm{paCO}_{2}$ with $\mathrm{p}$ value $=0.011$.

As regards $\mathrm{paO} 2$ and $\mathrm{O}_{2}$ saturation we recognized significant decrease in $\mathrm{paO}_{2}(95.9 \pm 1.5$ versus $91.0 \pm 1.5)$ with $\mathrm{p}$ value $=$ 0.015 , no significant increase in $\mathrm{O} 2$ saturation $(95.9 \pm 4.3$ versus $96.4 \pm 2,8)$ with $\mathrm{p}$ value $=0.09$, however they found significant decrease in $\mathrm{paO}_{2}$ and $\mathrm{O}_{2}$ saturation with $\mathrm{p}$ value $=0.011$.

Limitations of our study include the small number of enrolled patients. Moreover, operators were aware about timing of evaluation (before or after dialysis).

In conclusion, ultrasound performed at the bedside can detect lung water and intravascular overload and their reduction after dialysis in as yet asymptomatic patients.

Despite all the limitations, lung ultrasound remains an easy, harmless and feasible technique for monitoring hydration state, its response to dialysis, which should help in decreasing morbidity and mortality on long term.

These observations strongly support the use of lung ultrasound and inferior vena cava measurement in estimating volume overload and monitoring the response to therapy in hemodialysis.

\section{References:}

Basso F., b Milan Manani S., b C Cruz D.N., et al ... Comparison and Reproducibility of Techniques for Fluid Status Assessment in Chronic Hemodialysis Patients

Blood Purif. j 2013; 36:184-191.

Kalantar-Zadeh K, Regidor DL, Kovesdy CP et al : Fluid retention is associated with cardiovascular mortality in patients undergoing long term hemodialysis. Circulation 2009, 119(5):671-679 . www.scirj.org 
Noble VE, Murray AF, Capp R et al: Ultrasound assessment for extravascular lung water in patients undergoing hemodialysis. Time course for resolution. Chest 2009, 135(6):1433-1439.

Mallamaci F, Benedetto F a, Tripepi R, et al: Detection of pulmonary congestion by chest ultrasound in dialysis patients. JACCC a rdiovasc Imaging $2010,3: 586-594$.

Safa J, Noshad H, Ansarin K, et al: Saudi J Kidney Dis Transpl. 2014 Jul;25(4):781-7.

Trezzi M, Torzillo D, Ceriani E et al (2011): Lung ultraso-nography for the assessment of rapid extravascular water variation: evidence from hemodialysis patients. Intern Emerg Med 2013,8: 409- 415.

Vitturi N, Soattin M, Allemand E et al (2011) Thoracic ultrasonography: a new method for the work up of patients with dyspnea. J Ultrasound 14(3):147-151. 